\title{
The construction of contrast as a mechanism of attractivization of discourse
}

\author{
Aiuna Aleksandrovna Orsoeva ${ }^{1 *}$, Evgeniia Fyodorovna Serebrennikova ${ }^{1}$, Oksana Anatolievna Kaverina ${ }^{1}$ \\ ${ }^{1}$ Irkutsk State University, Department of Oriental and Regional Studies of the Asia-Pacific Region, 664003, Irkutsk, Karl Marx Street 1, \\ Russia
}

\begin{abstract}
The article discusses the role of eventfulness as one of the parameters of discourse and its relationship with the category of attractiveness in the study of the effectiveness of discourse. The position on the role of the construction of contrast in its various forms in the implementation of linguo-cognitive mechanisms of discourse attraction is substantiated. On the basis of representative texts of the promoting type of discourse, which are based on the construction of contrast, cognitive mechanisms of attraction are distinguished.
\end{abstract}

\section{Introduction}

In the conditions of a rapidly developing information society, the problem of the effectiveness of discourse, realized in different types of texts, becomes especially urgent for linguists. According to the theory of speech acts, the concept of "perlocutionary effect" $[1 ; 2]$ is substantiated in connection with the realization of intentionality and the achievement of a pragmatic effect derived from the illocutionary force of the speech act; the effectiveness of speech interaction is often associated with the implementation of the rules, "maxims of communication" [3].

\section{Theoretical basis of the study}

Within the framework of discourse research, various approaches are being developed; in particular, it raises the question of the effectiveness of an advertising text with a special pragmatic impact [4]; the text of the "promoting" type with a pronounced effect potential is implemented [5]. Linguists are actively involved in the development of methods and techniques for achieving the effect of influence in speech. Thus, discourse research is carried out in connection with the AIDA formula, with the help of which a certain level of influence on the thinking of the addressee is achieved [4].

As part of the development of the problem of the effectiveness of discourse, the question arises about its qualitative characteristics that affect its influencing potential in communication. For example, the category of eventfulness. [6]. Many works are devoted to the development of its aspects; the ontological status of an event and eventfulness is considered [7;8], perception of an event by human consciousness, linguistic ways to designating an event $[7 ; 9]$, textual representation of an event [10]. The ways to develop eventfulness of discourse as a category that has a direct impact on the success of discourse and determines the degree of its effectiveness are outlined [11].

We include the category of attractiveness, borrowed from the theory of synergetics, in the parameters related to the eventfulness of discourse [12]. The concepts of attractiveness and attractor are actively studied in modern linguistics [13], in text analysis [14], in discourse [15]. Language, as an open nonlinear sensegenerating system, is a subject to non-equilibrium states, and therefore, with a dynamic approach to its analysis, the notion of attractor is introduced to explain discursive processes and mechanisms of implementation - the area and the way of ordering an open non-equilibrium system.

At the same time, the essence of eventfulness is interpreted as the ability to change the state of affairs in the world in course and as a result of some action [16], primarily in the processes of communicative, cognitivediscursive activity. Thus, we consider it reasonable to consider the category of attractiveness within the framework of the dynamic approach as an integral quality of event discourse. At the same time, attractiveness is formed thanks to attraction - the activation of cognitive processes in communication with the help of attractors, which carry the main, central meaning and order the discrepancy and uncertainty constructed in the interpreter's mind, which makes discourse attractive, the property of attraction in the communicative space, that is, the quality of eventfulness. Attraction is viewed as a synergistic, creative phenomenon that influences the thinking of the addressee. This statement is based on the theory of discourse as a way of constructing "living" knowledge [17] in the processes of conceptualization [18] and discourse as an "alternative world" [19]. 
We believe that the attractiveness, and after it the eventfulness of discourse, is embodied with the help of cognitive mechanisms, characterized by the activation of the intellectual and emotional spheres due to the fact that the discourse is placed on the verge between incompatible phenomena, cognitive contrasts, the opposition of routine, familiarity, simplicity and consistency - originality, illogical, absurd and creative. They create coordinates of greater or lesser cognitive uncertainty by activating linguo-cognitive processes and, as a result, effectively manage communication [20].

One of the most representative ways of giving attractiveness to discourse (attractivization) is the construction of contrast. This phenomenon, along with the phenomenon of contradiction, was originally incorporated in the language worldview of an individual being an integral part of his mental world as one of the means of cognition, development of thinking and evaluation [21]. Contrast is understood as a sharply expressed opposition, revealed in the processes of understanding a certain object [22]. In philosophy, contradiction is viewed as the relationship between opposite, incompatible concepts, phenomena that, at the same time, depend on each other, are in unity, as a result of which development occurs. [23]. Thus, the basis of these phenomena is the interaction of the opposite, the comparison of the incomparable, the combination of the incompatible.

The contrast is based on the phenomenon of anomaly - logical inconsistency expressed in various ways, including logical contradictoriness, incompatibility of semantic components, simultaneous expression of different points of view, etc. Anomaly implies a deviation from the norm, violation of a pattern, both at the superficial and deep levels, the rethinking of which leads to the emergence of a contradiction. Contrast, expressed by means of antonymy, antithesis, paradox, etc., has a nonlinear structure, violates the usual structure of consciousness, thereby making the transition through the borders of ordinary logic [24]. Constructing contrast disrupts the association process, interrupts the inertia of world cognition, which gives prominence to the message, changes the direction of interpretation, thereby making an addressee to think, activate the emotional and rational spheres in the search for resolution of contradiction. Consciousness of the addressee always strives to solve the arising contradictions that impede the processes of categorization and classification, without which the process of cognition and assessment is impossible [25; 26]. The addressee, in an attempt to interpret the message, constructed according to the vector of difference from the ordinary, customary in cognition, focuses on this, trying to find the answer and organize the information [27].. As a result, it can be concluded that the structuring of a contradiction can have a significant influencing effect of a heuristic nature, as well as play a basic, decisive role in the formation of linguo-cognitive mechanisms, which, in turn, ensure the attractiveness and eventfulness of discourse.

We also include the discourse of a communicative event, defined as a discourse that creates or accompanies a reference situation, a state of affairs, an action that is organized with the aim of becoming an event in a communicative space, to a discourse of the "promoting" type. As an example, we can cite various events, meetings, elections, sports competitions, etc. This type of discourse aims to achieve the status of a communicative event in communication. One of the most representative types of promotional texts is advertising discourse, vividly representing all the characteristics of this type of discursive formation [5].

\section{Discussion}

The analysis focuses on modeling the cognitive mechanisms of attraction, which are structured on the basis of contrast.

The study analyzed the texts of the Russian-language and Korean media space, objectifying the discourse of a communicative event, for example, article headlines, slogans. These texts cover different spheres of human life, including social, economic and cultural spheres. The authors of the analyzed text will insert before themselves the goal of constructing a discourse that attracts attention and engages in an event, prompting the addresseeinterpreter to take certain actions, for example, buy a product, read an article, etc.

The research methodology comprises a dynamic approach to discourse analysis [19; 15], linguistic synergy positions [13], the theory of event and event categories [8; 10], media text / discourse theory [4], advanced text type theory [5], conceptual spaces theory [18]. The analysis uses a modeling method, methods of contextual and interpretive analysis. Contextual analysis of media texts of the promotion type and their interpretation revealed the following attraction mechanisms based on a contradiction constructed in the utterance / discourse in the form of contrast:

1) Structuring the paradox. The construction of the attractor occurs at the boundary of opposition. In such examples as "Classics with balanda (prison food)", "With a scalpel and a gun" some contradiction is constructed, opening up and intensifying the interpretative perspective of combining and representing a vivid example of a language game. In the example "With a scalpel and a gun," the first part of the perceived text / discourse following the context leads to the activation of the mental sphere of "medicine" associated with the conceptual sphere of healing, recovering from illness, giving help those who need it. And as follows from the perception and conceptualization of the second part of discourse, it should be understood in a completely different, opposite area of the "war" connected with the conceptual sphere of violence, death, grief and fear. The attractor creates a conceptual puzzle, and the addressee involuntarily seeks to understand, solve, decipher, which makes him think about the problem, share the author's feelings. The "classics", whose image is associated with the concepts of the majestic, the beautiful and the sublime, are compared with the "balanda", prison food, representing a sphere that is directly opposite, associated with something unpleasant, dishonorable, and even disgusting. 
Another example is a campaign encouraging teenagers to devote more time to reading books. The reading situation is compared with the situation of sports training, and the classics of Russian literature are presented as coaches: A.S. Pushkin, A.P. Chekhov and others. The material is presented in the form of creolized texts that combine verbal text ("Don't give up. A second wind will open on the $500^{\text {th }}$ page", "Start with small texts. Increase the load gradually") and the image of writers in the form of physical education teachers endowed with the attributes of modern coaches: uniforms, sports equipment, etc. The created paradox evokes an emotional reaction in perception at the border of the expected serious vision of the situation (reading the classics) and its unexpected comic vision in an attempt to combine these angles in a figurative interpretive grid of comprehension: the images of a classic writer and a modern physical education teacher, precise sports techniques and a way of reading voluminous classical works as time-consuming intellectual human activity, etc.

The realization of attractiveness on the basis of paradoxical structuring is also observed in the media texts of the Korean Internet space. One of the best examples is the promotion announcement of the series called "킬미 힐마" - (Korean: Kill me, heal me). TV shows are popular in the Republic of Korea. They are released every day, which leads to a high level of competition and the struggle for audience interest and attention. Therefore, in the process of promotion of the series, like any other product, in the strategy of better positioning is a constant search for formulas for the announcements and their slogans, which would attract the attention of the viewer and "inspire" him to watch. This example refers the addressee to the existential axiological confrontation of life and death, murdering and healing, absolute evil and absolute good. At the same time the imperative form creates the desired way of activating the deep motivational attitudes for understanding the proposed contrast, creating the effect of the need to connect the incompatible.

2) Breaking the pattern, overcoming the stereotype. This method of attrractivizing discourse arises in interpretive processes on the border of combining the real and the unreal, and has similar features to the previous method. Its peculiarity is that it is based on the use of judgments - doxa, for example, "Ice climbing. It's good for girls too". The basis of the contradiction is a violation of stereotypical everyday knowledge, including precedent phenomena. Thus, the effect of fascination is formed: at the time of violation of the ordinary, habitual, stereotypical line of cognition, consciousness can be subjected to the greatest, maximum level of influence. It is believed that extreme sports are intended to men, but the development of society, the strengthening of the active role of women in all spheres of life leads to the expansion of accessible areas that were previously considered purely "male". At the same time, this process has not completely broken the existing stereotypes yet. In its content, the message supports the emerging trend, placing its perception in the controversial area of social relations. The affective image of a girl engaged in ice climbing, reinforces the significance of the message as a kind of challenge to stereotypes. The message "For those who want to earn 45,000 rubles, working 2-3 hours a day" urges the reader to believe that, contrary to the generally accepted opinion about the difficulty of making a lot of money, it is possible to do this without doing much or working very hard.

A different, atypical vision of the world is contained in the title of the book 사람 이 악마 다 (Korean: People are evil). Despite existing criticism of humanity in various aspects, a direct comparison of a person with the worst in the world - evil creates a heuristic riddle, initiating the addressee to read the book in order to find out the reasons for such a categorical statement, to form their own opinion about its truth or falsity. Since the name generally refers to all people, each interpreter becomes a participant in the event, involved in a predictable discussion, caused by the natural, inborn desire of a person to protect his honor, not to associate himself with something negative.

The demonstration of overcoming the habitual, stereotyped knowledge is laid in the promotional text of the product of the South Korean company Samsung: 미세먼지 필터부터 냄새분해필터까지. ... 총 4 단계 의류 청정으로 더 깨꼿하게 관리. 리얼 케어 ... (Korean: From fine dust filter to odor decomposition filter. ... 4 steps cleaner than the total management of clean clothes. Real Care).

Unusual and unaccustomed one for understanding is the reality of the existence of a separate device for cleaning clothes, similar in function, but different in methods from the usual washing machine. In addition, the emergence of new functions is emphasized, such as getting rid of unpleasant odor, as well as combating the smallest dust, which is currently one of the most serious environmental problems in South Korea. The structuring of discourse is realized in interpretational processes on the border of combining the possible and the impossible in the axiological pragmatic "horizon of expectation" of the addressee.

3) Illogical construction, absurdization. In this case, discourse is attrativized by balancing, breaking the boundaries of the logical, attacking the coherence of thinking. In this case, the semantic coherence of consciousness is violated, the addressee begins to think according to the scenario given by the author of the message. The initial part of the message does not logically and semantically imply and does not correlate with the subsequent part. The text of a poster with the image of a participant in the demonstration against raising the retirement age can be a clear example: It's just interesting, whether ballerinas will also jump to 63 years old? It contradicts common sense that a ballerina can work at such an age as 63 years, since it is known that ballet dancers perform up to a maximum of 40 years, and at 60 years of age, it is physically impossible to do ballet. The degree of irony is enhanced by the choice of vocabulary - "jumping" instead of "working", which creates, along with the choice of the ballerina as 
an actant of the situation, the desired absurdly comic effect, constructing an "alternative world" as an "antiworld".

This kind of absurdization represents the integration of two levels of vision of the situation: the superficial the apparent, the deep - the "truth", initiating the transition from the first to the second, and thus setting empathy - orientation of interpretation of the situation by the addressee.

One more representative example is the title of the play "Yesterday Came Suddenly, Winnie the Pooh, or Goodbye, The Beatles", which is also a deliberate structuring of the absurd. The effect is enhanced by the fact that the discrepancy is constructed simultaneously at several levels: formally at the lexical, grammatical, morphological, and at the content level: farewell to a musical group, a character in a children's book, a certain time period. In this case, the addressee is faced with a heuristic riddle that must be solved in order to overcome the discomfort caused by misunderstanding, the inability to conceptualize and categorize new knowledge. Accordingly, the activation of the emotional and rational spheres occurs, and attention is completely focused on the presented riddle, which makes a certain challenge to solve it. The addressee is faced with the need to urgently and immediately resolve, remove the inconsistency that has arisen, which can only be done if the specified actions are performed, namely - to watch the performance, learn more about it, in order to understand how such phenomena of reality as the character of Winnie the Pooh, the Beatles and the time period can be combined. In this case, ordering of meanings facilitate the emergence of new meanings in the process of discoursing the message.

4) Implication of value status by opposition. This mechanism is formed according to the vector of emphasizing the novelty of the object under consideration. The very concept of "new" carries a contrast with the "old", "uninteresting", "unfashionable". The attractiveness of discourse is achieved not by actively promoting the status of novelty, but by pointing out the conceptual properties of novelty. We consider this mechanism in the text, promoting a new model of Samsung TV: 진정한 초고화질을 즐길 수 있는 $T V$. 눈 아에이 있는 것처럼 깊이감 있는 $8 K$ 화질. 3,300 만 개의 픽셀로 완성한 초고화질. $Q L E D ~ 8 K$ 는 Full $H D$ 대비 16 배, 4K UHD TV 대비 4 배 맣은 3,300 만 개의 픽셀을 갖춰 세밀한 표현이 가능합니다.... 세계가 인정한 - (Korean: This is the TV to enjoy true ultrahigh quality. The $8 K$ image quality is so deep that everything seems to be right in front of you. $8 \mathrm{~K}$ provides super high quality image with 33 million pixels. QLED $8 K$ is 16 times more than full HD and 4 times as many as $4 K$ UHD TV, with 33 million pixels).

This text is based on implication and play with contrast. "High quality" implies "bad quality", "color depth" - "dim color", "really clear image" - "muddy image". A feature of this discourse is its finalization the summarizing, explicable output of a contrast attractor that is recognized worldwide as a focus of expression. In this case, attraction is also achieved by using the intellectual and emotional sphere of the addressee, who is forced to look for an answer to a question, a riddle, which contributes to the achievement of the quality of eventfulness.

\section{Conclusions}

Thus, we can conclude that the basis for achieving the attractiveness of the discourse of a communicative event may be the construction of a contradiction, which has a significant influencing potential. In this case, attractiveness is achieved within the framework of overcoming contradictions in the processes of conceptualization and categorization of the addressee, prompting him to be involved in a communicative event. Meanwhile the ordering of meanings takes place and new meanings arise in the process of discoursing the message.

\section{References}

1. J. Austin How to Do Things with Words. Novoe v zarubezhnoy lingvistike, 17, 22-129 (1986)

2. J. Searle The classification of illocutionary acts. Novoe v zarubezhnoy lingvistike, 17, 170-194 (1986).

3. H.P. Grice Logic and conversation. Novoe v zarubezhnoy lingvistike, 16, 217-237 (1985)

4. E.V. Alexeenko, N.S. Bondarenko Analysis of basic models of the advertising process for impact on consumers. International Journal of the Humanities and Natural Sciences, 10(2), 13-15 (2018)

5. L.V. Ukhova Advertising text effectiveness. Bulletin of Kostroma State University, 1, 4-8. (2010)

6. N.D. Arutiunova Discourse. Linguistic encyclopedic dictionary, 136-137 (1998)

7. N.D. Arutiunova The Types of Linguistic Meanings: Value. Event. Fact, Moscow, Nauka, (1988)

8. V.Z. Demiankov 'Event' in semantics, pragmatics and text interpretation coordinates. Proceedings of the USSR Academy of Sciences. Series: Literature and Language, 4, 320-329 (1983)

9. V. E. Goldin Names of speech events, speech deeds, and genres of Russian speech. Speech genres, 1, 23-34. (1997)

10. V. D. Shevchenko Representation of event in various discourses. Actual problems of philology and pedagogical linguistics, 2(22), 35-39 (2016)

11. E.G. Treshcheva Event and Its Participants (Based on the Associative Fields of event stimuli). Bulletin of Saratov University. New series. Series Philology. Journalism, 11(1), 7-10 (2012)

12. G. Nikolis, I. Prigozhin Exploring complexity. Moscow, Mir, (1990)

13. L.V. Bronnik Cognitive linguosynergetics as a new stage in the science of language and thinking. Bulletin of Adyghe State University. Series 2: Philology and Art, 10, 29-31 (2000)

14. G.G. Moskalchuk How the synergetic effects appear in the text. Bulletin of Perm National Research 
Polytechnic University. Problems of linguistics and pedagogy, 2, 8-16 (2016)

15. S.N. Plotnikova, E.F. Serebrennikova The cognitive trajectory of discursivization: destination, strategy, technology. Bulletin of Irkutsk State Linguistic University, 1, 183-189 (2013)

16. V.A. Andreeva Event and fictional narrative. Bulletin of the Russian State Pedagogical University, 7, 44-56 (2006)

17. A.A. Zalevskaia Problem of knowledge in different angles. Cognitive linguistic studies, 2, 14-65 (2009)

18. G. Fauconnier Mentalspaces, languagemodalities, and conceptual integration. The new psychology of language: Cognitive and Functional approaches to Language structures, (1998)

19. Iu. S. Stepanov Alternative World. Discourse. Fact and Causality Principle. Language and science of the end of XX century, Moscow, 35-75 (1995)

20. E.F. Serebrennikova Polysemy: the aspect of attractiveness of a sign in communication. The multiplicity of language units in the cognitive aspect, 158-168 (2013)
21. M.K. Volf On the question of the Hegelian theory of contradiction. The philosophy of Hegel: the problems of dialectics, Moscow, 145-165 (1987)

22. T.F. Efremova, New dictionary of the modern Russian language. Definition dictionary and wordformation dictionary. The Russian language, (2000) 23. Philosophical Encyclopedic Dictionary. Ed. by L.F. Ilichev, P.N. Fedoseev, S.M. Kovalev, V.G. Panov. Moscow, Soviet Encyclopedia, (1983)

24. M.V. Gribova Contrasting as one of the techniques of language manipulation in advertising. Socioeconomic phenomena and processes, 8(30), 29-35 (2011) 25. N.N. Boldyrev Properties and boundaries of evaluation categories in the light of new ideas about the processes of categorization. Language categories: boundaries and properties: materials of the International Conference, Moscow, 14-16 (2004)

26. V.M. Allakhverdov Consciousness as a paradox. Saint Petersburg, DNK, (2000)

27. L. Festinger Theory of cognitive dissonance. Saint Petersburg, Uventa, (1999) 